\title{
USO DE LODO DE ESGOTO NA REESTRUTURAÇÃO DE SOLO DEGRADADO ${ }^{(1)}$
}

\author{
Fabiana da Silva de Campos ${ }^{(2)}$ \& Marlene Cristina Alves ${ }^{(3)}$
}

\begin{abstract}
RESUMO
O uso do solo nem sempre dá lugar a um novo sistema ecológico sustentável, seja de lavouras, seja de pastagens. Com isso, solos utilizados intensamente e de forma inadequada são levados à degradação. Nesse sentido, este trabalho teve como objetivo estudar a influência do lodo de esgoto na recuperação de propriedades físicas de um Latossolo Vermelho degradado, cultivado há 2,5 anos com eucalipto (Eucalyptus citriodora Hook) e braquiária (Brachiaria decumbens) no município de Selvíria, MS. O delineamento experimental utilizado foi em blocos casualizados com seis tratamentos e quatro repetições. Os tratamentos foram: 1vegetação de Cerrado; 2-solo exposto sem tratamento para recuperação; 3 -solo cultivado com eucalipto e braquiária sem uso do lodo de esgoto e adubação mineral; 4-solo cultivado com eucalipto e braquiária com adubação mineral; 5-solo cultivado com eucalipto e braquiária com uso de $30 \mathrm{Mg} \mathrm{ha}^{-1}$ de lodo de esgoto; e 6-solo cultivado com eucalipto e braquiária com uso de $60 \mathrm{Mg} \mathrm{ha}^{-1}$ de lodo de esgoto. Nas camadas do solo de $0,00-0,05 ; 0,05-0,10 ; 0,10-0,20 ;$ e $0,20-0,30 \mathrm{~m}$, foram estudadas as propriedades físicas do solo: macroporosidade, microporosidade; porosidade; $\mathrm{e}$ densidade do solo. Na braquiária foram avaliadas as matérias verde e seca e, no eucalipto, a altura média de planta e o DAP (diâmetro à altura do peito). Concluiuse que o solo estudado está sendo recuperado por meio dos tratamentos estabelecidos. Dentre eles, destacam-se os tratamentos com a utilização do lodo, que influenciaram as propriedades físicas do solo, proporcionaram mais rendimentos de matérias verde e seca da braquiária e promoveram maior crescimento das plantas de eucalipto. $O$ crescimento vegetal, a densidade do solo, a porosidade total e a macroporosidade foram os melhores indicadores da recuperação do solo.
\end{abstract}

Termos de indexação: matéria orgânica, recuperação do solo, Latossolo Vermelho, eucalipto, Brachiaria.

\footnotetext{
(1) Parte do trabalho de Mestrado desenvolvido no Programa de Pós-Graduação em Sistemas de Produção da Faculdade de Engenharia de Ilha Solteira - UNESP/Campus de Ilha Solteira. Recebido para publicação em março de 2007 e aprovado em maio de 2008.

${ }^{(2)}$ Mestranda da Faculdade de Engenharia, Universidade Estadual Paulista - UNESP. Caixa Postal 31, CEP 15385-000 Ilha Solteira (SP). Bolsista CAPES. E-mail: fscampos@aluno.feis.unesp.br

(3) Professora Adjunta, Departamento de Fitossanidade, Engenharia Rural e Solo, Faculdade de Engenharia, UNESP. E-mail: mcalves@agr.feis.unesp.br
} 


\title{
SUMMARY: USE OF SEWAGE SLUDGE TO RESTRUCTURE A DEGRADED OXISOL
}

\begin{abstract}
The soil use not always result in an ecological sustainable system. An intense and inadequate soil use leads to soil degradation. In this sense, this study aimed to investigate the influence of sewage sludge on the recovery of physical properties of a degraded Oxisol, cultivated for 2.5 years with eucalyptus (Eucalyptus citriodora Hook) and Brachiaria grass (Brachiaria decumbens), in Selvíria, MS, Brazil. Six treatments were evaluated in an experiment in a randomized block design with four replications: (1) Savannah; (2) exposed soil without treatment for recovery; (3) soil under eucalyptus and pasture (without application of sewage sludge or mineral fertilization); (4) soil under eucalyptus and pasture with mineral fertilization; (5) soil under eucalyptus and pasture with application of $30 \mathrm{Mg} \mathrm{ha}^{-1}$ sewage sludge, and (6) soil under eucalyptus and pasture with application of $60 \mathrm{Mg} \mathrm{ha}^{-1}$ sewage sludge. In the soil layers $0.00-0.05 ; 0.05-0.10 ; 0.10-0.20$ and of $0.20-0.30 \mathrm{~m}$, the following physical properties were studied: macroporosity; microporosity; soil porosity, and bulk density. Green and dry mass of pasture and height and DBH of eucalyptus were evaluated. It was concluded that the studied soil is a recovery process. The treatments with sludge application were more effective because of their influence on the soil physical properties, besides resulting in higher green and dry mass yield in brachiaria and increased growth of eucalyptus trees. The best indicators of soil recovery were plant development, soil bulk density, total porosity, and macroporosity.
\end{abstract}

Index terms: organic matter, soil recovery, Oxisol, eucalyptus, Brachiaria.

\section{INTRODUÇÃO}

O uso agrícola do lodo de esgoto como adubo orgânico é considerado hoje como a alternativa mais promissora de disposição final desse resíduo, principalmente na recuperação de áreas degradadas.

Várias técnicas têm sido utilizadas com o objetivo de recuperar solos degradados, e a maioria combina práticas mecânicas, que visam romper camadas compactadas, com a adição de matéria orgânica (De Maria et al., 1999). Várias fontes de matéria orgânica também têm sido utilizadas, como a do lodo de esgoto, que favorece a formação de agregados, facilitando a penetração das raízes e a vida microbiana, aumenta a resistência do solo à erosão, por estabilizar a estrutura do solo e aumentar a capacidade de retenção de água, tornando as culturas mais resistentes à seca, além de fornecer nutrientes para as plantas, propiciando maior rendimento de matéria verde e seca (Tsutiya, 2001).

Como fonte alternativa para a adubação orgânica, o lodo de esgoto vem, de maneira crescente, revelandose como um importante insumo agrícola, de interesse na recomposição de solos degradados, bem como na fertilização das culturas, de preferência aquelas que não são de consumo direto pelos seres humanos. $O$ reflorestamento, por não ser uma atividade que envolve produtos para consumo alimentar e pelo fato de poder ser instalado em áreas distantes de núcleos urbanos, com acesso restrito a pessoas e animais, apresenta grande vantagem em relação às culturas comerciais no tocante ao uso de lodo de esgoto. Sua aplicação em áreas agrícolas, floresta e em áreas degradadas traz benefícios às propriedades físicas do solo, pois o lodo é um condicionador que facilita a formação de agregados e melhora a infiltração, a retenção de água e a aeração do solo (Tsutiya, 2001).

Estudos realizados por Colodro \& Espíndola (2006) e Alves et al. (2007) mostram que o crescimento de plantas de eucalipto e de espécies nativas de Cerrado foi maior quando se utilizou lodo de esgoto. Observouse também melhoria das propriedades físicas, químicas e biológicas do solo.

Em trabalho realizado na Fazenda Experimental de Londrina, Paraná, em um Latossolo Vermelho eutroférrico, verificou-se, após dois anos de tratamento com lodo de esgoto, que houve tendência na formação de agregados maiores (Barbosa et al., 2002). Também De Maria et al. (2007) verificaram, em solos que receberam lodo, aumento gradativo no diâmetro dos agregados, de acordo com a quantidade aplicada. Os autores ainda mencionam que a estabilidade dos agregados em água foi maior em solos que receberam lodo, pois estes ficaram mais resistentes às ações hídricas, devido aos componentes e benefícios do lodo de esgoto.

Tendo em vista os efeitos positivos do uso do lodo de esgoto na recuperação de propriedades do solo e na busca por técnicas que possam contribuir para a regeneração de ecossistemas, principalmente aqueles 
com baixa resiliência, isto é, quando seu retorno ao estado anterior pode não ocorrer ou ser extremamente lento, desenvolveu-se esta pesquisa com o objetivo de estudar a influência do lodo de esgoto na recuperação de algumas propriedades físicas de um Latossolo Vermelho degradado, remanescente da área de "empréstimo" usada para a construção da Usina Hidrelétrica de Ilha Solteira, SP, que está sendo cultivado há 2,5 anos com eucalipto. Entende-se como "área de empréstimo" os locais onde se retiram materiais para complementar os volumes de solos necessários à execução das terraplanagens e fundações das barragens (Lopes \& Queiroz, 1994).

\section{MATERIAL E MÉTODOS}

O trabalho foi conduzido no município de Selvíria, MS. A área experimental está localizada na margem direita do Rio Paraná, apresentando as coordenadas geográficas de $51^{\circ} 22^{\prime}$ de longitude e $20^{\circ} 22^{\prime}$ de latitude sul, com altitude média de $327 \mathrm{~m}$. A região apresenta médias anuais de: precipitação pluvial de $1.370 \mathrm{~mm}$, temperatura de $23,5{ }^{\circ} \mathrm{C}$ e umidade relativa do ar entre 70 e $80 \%$. O tipo climático segundo Köppen é Aw (clima tropical úmido, com estação chuvosa no verão e seca no inverno). O período chuvoso se estende de outubro a março; os meses de dezembro, janeiro e fevereiro constituem o trimestre mais chuvoso, e junho, julho e agosto, ao mais seco. A vegetação natural da área de estudo era o Cerrado.

O solo original é um Latossolo Vermelho-Escuro (Demattê, 1980) e, de acordo com a nomenclatura do Sistema Brasileiro de Classificação do Solo (Embrapa, 1999), é um Latossolo Vermelho distrófico textura franco-argilo-arenosa (274 $\mathrm{g} \mathrm{kg}^{-1}$ de argila, 526 de areia e 200 de silte), profundo e muito intemperizado, relevo suave a plano. O local de instalação da pesquisa é uma área degradada, de onde foi retirada uma camada de solo de 8,60 m de espessura para utilização na terraplanagem e fundação na construção da Usina Hidrelétrica de Ilha Solteira, SP.

O delineamento experimental utilizado foi em blocos casualizados, com seis tratamentos e quatro repetições, instalados em fevereiro de 2003. Os tratamentos foram constituídos dos seguintes usos e manejos: T1 - vegetação natural de Cerrado; T2 solo exposto (sem tratamento para recuperação); T3solo cultivado com eucalipto e braquiária, sem aplicação de lodo de esgoto e adubo mineral; T4 - solo cultivado com eucalipto e braquiária, com adubação mineral de acordo com a necessidade da cultura e a análise do solo; T5 - solo cultivado com eucalipto e braquiária com uso de $30 \mathrm{Mg} \mathrm{ha}^{-1}$ de lodo de esgoto (base seca); e T6 - solo cultivado com eucalipto e braquiária com uso de $60 \mathrm{Mg} \mathrm{ha}^{-1}$ de lodo de esgoto (base seca). Cada parcela ocupou uma área de $120 \mathrm{~m}^{2}$ $(12 \times 10 \mathrm{~m})$.
Pela grande circulação de máquinas na área, o solo remanescente apresentava-se compactado, requerendo mobilização para seu uso agrícola. Dessa forma, preparou-se a área efetuando-se a limpeza superficial, subsolagem e revolvimento do solo. Os tratos culturais foram feitos conforme a necessidade, com capinas efetuadas mecanicamente.

Nos tratamentos solo cultivado com eucalipto e braquiária, sem aplicação de lodo de esgoto e adubo mineral; solo cultivado com eucalipto e braquiária com adubação mineral; solo cultivado com eucalipto e braquiária com $30 \mathrm{Mg} \mathrm{ha}^{-1}$ de lodo de esgoto; e solo cultivado com eucalipto e braquiária com $60 \mathrm{Mg} \mathrm{ha}^{-1}$ de lodo de esgoto foi implantada a cultura de eucalipto (Eucalyptus citriodora Hook) com espaçamento entre plantas de $2 \times 1,5 \mathrm{~m}$, totalizando, portanto, 40 plantas por parcela e 640 plantas no experimento; foi também semeada braquiária (Brachiaria decumbens) a lanço, com os objetivos de contribuir para o aumento de matéria orgânica do solo e reduzir inicialmente a elevada dose de $\mathrm{N}$ adicionada ao solo, em razão das doses de lodo utilizadas. Essa operação foi necessária para segurança quanto ao impacto ambiental, o que rediziu o risco de contaminação do lençol freático, devido a algumas condições que favorecem a volatilização de amônia, como temperatura elevada, déficit de saturação do ar em amônia, baixo teor de água, rápida evaporação de água, baixa CTC e forma de aplicação do lodo (Mello et al., 1984). A escolha da braquiária foi devida a sua capacidade de contribuir para o aporte de $\mathrm{C}$, uma vez que apresenta alta relação $\mathrm{C} / \mathrm{N}$, e por ter baixa exigência quanto à fertilidade do solo.

O lodo de esgoto espalhado na superfície e incorporado com enxada rotativa foi obtido da SANEAR (Saneamento de Araçatuba), localizada no município de Araçatuba, SP, efluente predominantemente de origem doméstica, com umidade de $0,84 \mathrm{~kg} \mathrm{~kg}^{-1}$. O teor de metais pesados é baixo e para alguns elementos é nulo (Quadros 1 e 2).

Para as análises físicas do solo foram coletadas amostras em quatro profundidades do solo: 0,00-0,05; 0,05-0,10; 0,10-0,20; e 0,20-0,30 m. As amostras foram coletadas 2,5 anos após a implantação do experimento.

As propriedades físicas do solo analisadas foram: densidade do solo e porosidade total, pelo método do anel volumétrico; microporosidade, pelo método da mesa de tensão com coluna de água de $0,60 \mathrm{~m}$; e a macroporosidade foi calculada por diferença entre a porosidade total e a microporosidade (Quadro 3). Todas as avaliações foram realizadas de acordo com a Embrapa (1997).

$\mathrm{Na}$ cultura de eucalipto (Eucalyptus citriodora Hook). avaliaram-se a altura média das plantas e o $\mathrm{DAP}$ (diâmetro à altura do peito) aos 2,5 anos. Para a braquiária (Brachiaria decumbens), analisou-se a produção de matéria verde e seca. Para realizar essas 
Quadro 1. Análise química do lodo de esgoto da ETE Araçatuba-SP. Ensaio de Lixiviação

\begin{tabular}{|c|c|c|}
\hline Elemento químico & Resultado & Limite máximo \\
\hline & $\mathrm{mg} \mathrm{L}^{-1}$ & $\mathrm{~L}^{-1}$ \\
\hline Arsênico & $\mathrm{Nd}$ & 5,0 \\
\hline Bário & 2,3 & 100,0 \\
\hline Cádmio & 0,003 & 0,5 \\
\hline Chumbo & 0,120 & 5,0 \\
\hline Cromo Total & 0,03 & 5,0 \\
\hline Fluoretos & 1,29 & 150,0 \\
\hline Mercúrio & $\mathrm{Nd}$ & 0,1 \\
\hline Prata & $\mathrm{Nd}$ & 5,0 \\
\hline Selênio & $\mathrm{Nd}$ & 1,0 \\
\hline
\end{tabular}

Tempo total de lixiviação: $24 \mathrm{~h}$. Volume total do líquido obtido: $1.603 \mathrm{~mL}$. Volume de ácido acético adicionado: 3,0 mL. pH inicial: 5,28/pH final: 5,01. Descrição do material analisado: lodo da ETE. Aspecto: massa escura e úmida. Métodos de análises baseados na $20^{\text {a }}$ edição do "Standard Methods for The Examination of Water and Wastewater". Nd: não detectado; sólidos no lodo desidratado: $15,6 \%$. Análises efetuadas segundo a NBR 10.004 - Resíduos Sólidos.

análises, foram coletadas plantas contidas em $1 \mathrm{~m}^{2}$, de dois pontos de cada parcela. As matérias verde e seca foram determinadas por pesagem, e a matéria seca foi colocada para secagem em estufa a $60-70{ }^{\circ} \mathrm{C}$ até atingir massa constante.

Para as propriedades físicas do solo, realizaram-se contrastes entre a área de vegetação natural e demais tratamentos; entre o solo degradado (exposto) e demais tratamentos; entre o solo cultivado com eucalipto e braquiária sem adubação mineral e lodo de esgoto e demais tratamentos; entre a área com adubação mineral e $60 \mathrm{Mg} \mathrm{ha}^{-1}$ de lodo de esgoto; e entre a área com $30 \mathrm{Mg} \mathrm{ha}^{-1}$ de lodo de esgoto e $60 \mathrm{Mg} \mathrm{ha}^{-1}$ de lodo de esgoto. Os resultados referentes às características das plantas foram analisados efetuando-se a análise de variância e o teste de Tukey para as comparações de média a $5 \%$. Foi usado o programa computacional SAS (Schlotzhaver \& Littell, 1997) para a realização da análise estatística.

\section{RESULTADOS E DISCUSSÃO}

Para a macroporosidade, observou-se que em todas as profundidades de solo estudadas não houve diferença significativa entre o contraste do tratamento com vegetação natural de Cerrado e os demais (Quadro 4), o que significa que os tratamentos de recuperação obtiveram bom desempenho, ou seja, aproximaramse das condições naturais do solo estudado. Analisando a macroporosidade, pode-se observar que os tratamentos de recuperação estão modificando positivamente esta propriedade no solo degradado, pois proporcionaram maior valor de macroporos quando comparado com o solo exposto (Quadro 5). Resultados semelhantes foram observados por Melo et al. (2004), que, estudando o efeito da adição de lodo de esgoto em propriedades físicas do solo, observaram que a incorporação de $50 \mathrm{Mg} \mathrm{ha}^{-1}$ de lodo aumentou a macroporosidade na superfície do solo.

Observando os valores médios de macroporosidade (Quadro 5) nos diversos tratamentos, verificou-se que os valores para o solo exposto encontram-se abaixo do valor considerado crítico de $0,10 \mathrm{~m}^{3} \mathrm{~m}^{-3}$ para um bom crescimento das plantas (Baver et al., 1972; Greenland,

Quadro 2. Resultados das análises químicas do lodo de esgoto utilizado

\begin{tabular}{|c|c|c|c|c|c|c|c|c|c|c|c|c|}
\hline MO & $\mathbf{N}$ & $\mathbf{P}$ & $\mathbf{K}$ & $\mathrm{Ca}$ & $\mathbf{M g}$ & $\mathbf{S}$ & B & $\mathrm{Cu}$ & $\mathrm{Fe}$ & Mn & $\mathrm{Zn}$ & Umidade \\
\hline $\mathrm{g} \mathrm{dm}^{-3}$ & & & - $\quad \mathrm{g} \mathrm{kg}$ & & & & & & $\mathrm{mg} \mathrm{kg}^{-1}$ & & - & $\mathrm{kg} \mathrm{kg}^{-1}$ \\
\hline 200 & 71,26 & 18,79 & 15,14 & 11,06 & 3,44 & 7,78 & 16,37 & 160,04 & 960,6 & 115,74 & 583,48 & 0,85 \\
\hline
\end{tabular}

Quadro 3. Valores médios de porosidade total, macroporosidade, microporosidade e densidade do solo degradado antes do preparo de solo, em dezembro de 2002

\begin{tabular}{ccccc}
\hline \multirow{2}{*}{ Profundidade } & Macroporosidade & Microporosidade & Porosidade total & Densidade do solo \\
& 0,08 & $\mathrm{~m}^{3} \mathrm{~m}^{-3}$ & & $\mathrm{~kg} \mathrm{dm}^{-3}$ \\
$0,00-0,05$ & 0,09 & 0,23 & 0,31 & 1,70 \\
$0,05-0,10$ & 0,08 & 0,24 & 0,33 & 1,68 \\
$0,10-0,20$ & 0,07 & 0,25 & 0,33 & 1,68 \\
$0,20-0,40$ & 0,24 & 0,31 & 1,80 \\
\hline
\end{tabular}


Quadro 4. Teste de significância para os contrastes entre os tratamentos referentes às propriedades físicas do solo, para as profundidades de $0,00-0,05 ; 0,05-0,10 ; 0,10-0,20$ e de $0,20-0,40 \mathrm{~m}$

\begin{tabular}{|c|c|c|c|c|c|}
\hline \multirow{2}{*}{ Propriedade } & \multicolumn{5}{|c|}{ Contraste entre tratamento } \\
\hline & $1 \times$ demais & $2 \times$ demais & $3 \times$ demais & $4 \times 6$ & $5 \times 6$ \\
\hline \multicolumn{6}{|c|}{ Propriedades físicas do solo - profundidade de $0,00-0,05 \mathrm{~m}$} \\
\hline Macroporosidade & NS & * & NS & NS & NS \\
\hline Microporosidade & NS & NS & NS & NS & NS \\
\hline Porosidade Total & NS & $*$ & NS & NS & NS \\
\hline Densidade do solo & NS & * & NS & NS & NS \\
\hline \multicolumn{6}{|c|}{ Propriedades físicas do solo - profundidade de $0,05-0,10 \mathrm{~m}$} \\
\hline Macroporosidade & NS & NS & NS & NS & NS \\
\hline Microporosidade & NS & NS & NS & NS & NS \\
\hline Porosidade Total & NS & * & NS & NS & * \\
\hline Densidade do solo & * & * & NS & NS & * \\
\hline \multicolumn{6}{|c|}{ Propriedades físicas do solo - profundidade de $0,10-0,20 \mathrm{~m}$} \\
\hline Macroporosidade & NS & * & NS & NS & NS \\
\hline Microporosidade & * & * & NS & NS & NS \\
\hline Porosidade Total & NS & * & NS & NS & NS \\
\hline Densidade do solo & * & * & NS & NS & NS \\
\hline \multicolumn{6}{|c|}{ Propriedades físicas do solo - profundidade de $0,20-0,30 \mathrm{~m}$} \\
\hline Macroporosidade & NS & * & NS & NS & NS \\
\hline Microporosidade & NS & NS & NS & NS & $\mathrm{NS}$ \\
\hline Porosidade Total & NS & * & NS & NS & NS \\
\hline Densidade do solo & * & * & NS & NS & NS \\
\hline
\end{tabular}

Legenda: $1=$ Cerrado, $2=$ Solo exposto, $3=$ Solo s/adubação, 4= Adubação mineral, $5=30 \mathrm{Mg}$ ha $^{-1}$ de lodo de esgoto, $6=60 \mathrm{Mg}$ ha ${ }^{-1}$ de lodo de esgoto. *: significativo a $5 \%$; NS: não significativo pelo teste F.

Quadro 5. Valores médios de macroporosidade e microporosidade para os tratamentos estudados nas profundidades de $0,00-0,05 ; 0,05-0,10 ; 0,10-0,20 ;$ e $0,20-0,30 \mathrm{~m}$

\begin{tabular}{|c|c|c|c|c|}
\hline \multirow{2}{*}{ Tratamento } & \multicolumn{4}{|c|}{ Profundidade do solo (m) } \\
\hline & $0,00-0,05$ & $0,05-0,10$ & $0,10-0,20$ & $0,20-0,30$ \\
\hline \multicolumn{5}{|c|}{ Macroporosidade do solo $\left(\mathrm{m}^{3} \mathrm{~m}^{-3}\right)$} \\
\hline Cerrado & 0,13 & 0,10 & 0,08 & 0,07 \\
\hline Solo exposto & 0,06 & 0,07 & 0,04 & 0,05 \\
\hline Solo $\mathrm{s}$ em adubação & 0,16 & 0,10 & 0,10 & 0,09 \\
\hline Ad. mineral & 0,13 & 0,10 & 0,10 & 0,08 \\
\hline $30 \mathrm{Mg} \mathrm{ha}^{-1}$ & 0,12 & 0,08 & 0,07 & 0,07 \\
\hline $60 \mathrm{Mg} \mathrm{ha}^{-1}$ & 0,15 & 0,14 & 0,07 & 0,07 \\
\hline $\mathrm{CV}(\%)$ & 40,67 & 37,90 & 45,55 & 22,52 \\
\hline \multicolumn{5}{|c|}{ Microporosidade do solo $\left(\mathrm{m}^{3} \mathrm{~m}^{-3}\right)$} \\
\hline Cerrado & 0,29 & 0,30 & 0,30 & 0,30 \\
\hline Solo exposto & 0,29 & 0,26 & 0,26 & 0,27 \\
\hline Solo s em adubação & 0,28 & 0,29 & 0,28 & 0,27 \\
\hline Ad. mineral & 0,28 & 0,28 & 0,28 & 0,27 \\
\hline $30 \mathrm{Mg} \mathrm{ha}^{-1}$ & 0,29 & 0,27 & 0,28 & 0,27 \\
\hline $60 \mathrm{Mg} \mathrm{ha}^{-1}$ & 0,28 & 0,28 & 0,27 & 0,28 \\
\hline CV (\%) & 12,34 & 8,69 & 7,30 & 9,44 \\
\hline
\end{tabular}


1981), o mesmo ocorrendo para os tratamentos com $30 \mathrm{Mg} \mathrm{ha}^{-1}$ de lodo de esgoto nas profundidades de $0,05-0,10,0,10-0,20$ e $0,20-0,30 \mathrm{~m}$ e com $60 \mathrm{Mg}^{-1}$ de lodo de esgoto nas profundidades de 0,10-0,20 e 0,20-0,30 m. Esse comportamento reflete a condição de degradação da estrutura, ou seja, a camada compactada. Para Kiehl (1979), um solo ideal é aquele que apresenta $1 / 3$ de macroporos dos $0,50 \mathrm{~m}^{3} \mathrm{~m}^{-3}$ ocupados pelos espaços vazios do solo, isto é, $0,17 \mathrm{~m}^{3} \mathrm{~m}^{-3}$.

Para a microporosidade apenas nos contrastes dos tratamentos com vegetação natural de Cerrado $\mathrm{x}$ demais e solo exposto $\mathrm{x}$ demais, na profundidade de 0,10-0,20 m, houve diferença significativa. Quanto às demais profundidades e contrastes, não houve diferença significativa (Quadro 4). No caso do contraste solo exposto $\mathrm{x}$ demais, isso significa que os tratamentos de recuperação não estão atuando de forma eficiente na alteração dessa propriedade no solo degradado, pois está igual à condição do solo exposto, resultados que concordam com os de Melo et al. (2004) e Jorge et al. (1991).

Para a porosidade total do solo no contraste vegetação natural de Cerrado $\mathrm{x}$ demais, também não houve diferença significativa em todas as profundidades de solo estudadas (Quadro 4). Isso significa que a porosidade total do solo em recuperação está semelhante à do solo original. Portanto, os tratamentos de recuperação se mostraram eficazes na recuperação da porosidade total do solo (Quadro 6). Verificou-se aumento significativo da porosidade total comparando-se os tratamentos usados para a recuperação do solo com a condição de solo degradado (exposto). Esse comportamento discorda dos de Jorge et al. (1991), que, estudando um Latossolo VermelhoEscuro argiloso, não observaram efeitos sobre a porosidade total determinada após quatro anos de aplicação de lodo de esgoto em doses de até $80 \mathrm{Mg} \mathrm{ha}^{-1}$, em forma parcelada ou em uma única vez. Entretanto, resultados semelhantes ao dessa pesquisa foram observados por Pagliai et al. (1981), que observaram aumento da porosidade total do solo com a adição de lodo de esgoto. Os efeitos dos tratamentos de recuperação na porosidade total do solo foram confirmados pela significância verificada no contraste solo exposto $\mathrm{x}$ demais (Quadro 4) para todas as profundidades de solo estudadas.

Com relação à densidade do solo, pode-se verificar que os tratamentos estavam recuperando essa propriedade física na profundidade de 0,00-0,05 m, pois eles diferiram da condição do solo exposto e apresentaram menor e não-significativo valor de densidade do solo (contraste vegetação natural de Cerrado x demais, Quadro 4). Para as demais profundidades do solo (Quadro 4) verificou-se que, entre o contraste do tratamento com vegetação natural de Cerrado $\mathrm{x}$ demais, houve diferença estatística para a densidade do solo. Isso significa que os tratamentos de recuperação não alteraram essa propriedade nas profundidades abaixo de $0,05 \mathrm{~m}$. O comportamento na profundidade superficial do solo (0,00-0,05 m) está de acordo com aquele observado por Martens \& Frankenberger Jr. (1992), que, em estudo, com duração de 25 meses, conduzido para avaliar os efeitos de esterco de galinha, lodo de esgoto, palha de cevada e alfafa fresca sobre propriedades físicas de um solo de textura média, observaram que a densidade do solo diminuiu em relação à testemunha quando fizeram a aplicação de três doses desses materiais (25 $\mathrm{Mg} \mathrm{ha}^{-1}$ cada, no início do experimento, após 10 meses e após 18 meses).

Analisando os valores médios de densidade do solo em todas as profundidades estudadas, exceto a de 0,00 0,05 m (Quadro 6), observou-se que os tratamentos de recuperação apresentaram maior valor de densidade do solo quando comparado com a vegetação natural de Cerrado, reforçando a hipótese de que os tratamentos com degradação da estrutura apresentaram maiores valores de densidade do solo. Esses resultados estão de acordo com Alves (1992) e Veiga et al. (1994), que observaram, em camadas compactadas, aumento da densidade do solo resultante do aumento da quantidade de sólidos em relação ao volume de poros e predomínio de microporos, nos quais o movimento da água e do ar era dificultado, diminuindo, dessa forma, a drenagem interna do solo comandada pela estrutura.

Os tratamentos de recuperação não estavam sendo eficazes na modificação da densidade do solo degradado, pois apresentaram maior valor de densidade comparado ao do Cerrado (Quadro 6), indicando compactação nas profundidades estudadas. Segundo De Maria et al. (1999) e Alves et al. (2007), a compactação ocorria com o aumento da sua densidade do solo e com a conseqüente diminuição da porosidade total e da macroporosidade.

Para o contraste do tratamento solo sem adubação $\mathrm{x}$ demais, isto é, tratamento com o solo cultivado com eucalipto sem adubação (mineral e, ou, orgânica) versus solo cultivado com eucalipto usando adubação mineral e adubação orgânica, não houve significância para todas as propriedades físicas estudadas, significando que os tratamentos de recuperação estavam semelhantes aos sem adubação (mineral ou orgânica) na recuperação do solo degradado. As propriedades físicas do solo estudado não estavam sensíveis para detectar diferenças entre os tratamentos de recuperação. O mesmo ocorreu para os contrastes entre os tratamentos de recuperação (solo com eucalipto e adubação mineral x solo com eucalipto e uso de $60 \mathrm{Mg} \mathrm{ha}{ }^{-1}$ de lodo de esgoto e solo com eucalipto e uso de $30 \mathrm{Mg} \mathrm{ha}^{-1}$ de lodo de esgoto x solo com eucalipto e uso de $60 \mathrm{Mg} \mathrm{ha}^{-1}$ de lodo de esgoto).

Entre os tratamentos de recuperação, verificou-se que para o contraste solo com eucalipto e uso de $30 \mathrm{Mg}$ ha-1 de lodo de esgoto x solo com eucalipto e uso de $60 \mathrm{Mg} \mathrm{ha}^{-1}$ de lodo de esgoto (Quadro 4) houve diferença significativa somente para porosidade total e densidade do solo na profundidade de 0,05-0,10 m. 
Quadro 6. Valores médios de porosidade total e densidade do solo para os tratamentos estudados nas profundidades de $0,00-0,05 ; 0,05-0,10 ; 0,10-0,20 ;$ e $0,20-0,30 \mathrm{~m}$

\begin{tabular}{|c|c|c|c|c|}
\hline \multirow{2}{*}{ Tratamento } & \multicolumn{4}{|c|}{ Profundidade (m) } \\
\hline & $0,00-0,05$ & $0,05-0,10$ & $0,10-0,20$ & $0,20-0,30$ \\
\hline \multicolumn{5}{|c|}{ Porosidade total do solo $\left(\mathrm{m}^{3} \mathrm{~m}^{-3}\right)$} \\
\hline Cerrado & 0,42 & 0,41 & 0,38 & 0,37 \\
\hline Solo exposto & 0,35 & 0,33 & 0,30 & 0,32 \\
\hline Solos em adubação & 0,44 & 0,39 & 0,38 & 0,36 \\
\hline Ad. mineral & 0,41 & 0,38 & 0,38 & 0,35 \\
\hline $30 \mathrm{Mg} \mathrm{ha}^{-1}$ & 0,41 & 0,36 & 0,35 & 0,34 \\
\hline $60 \mathrm{Mg} \mathrm{ha}^{-1}$ & 0,43 & 0,42 & 0,34 & 0,36 \\
\hline CV (\%) & 7,02 & 6,87 & 9,56 & 7,63 \\
\hline \multicolumn{5}{|c|}{ Densidade do solo $\left(\mathrm{kg} \mathrm{dm}^{-3}\right)$} \\
\hline Cerrado & 1,40 & 1,44 & 1,51 & 1,51 \\
\hline Solo exposto & 1,76 & 1,78 & 1,89 & 1,88 \\
\hline Solo s em adubação & 1,33 & 1,54 & 1,62 & 1,70 \\
\hline Ad. mineral & 1,43 & 1,55 & 1,59 & 1,69 \\
\hline $30 \mathrm{Mg} \mathrm{ha}^{-1}$ & 1,47 & 1,61 & 1,68 & 1,76 \\
\hline $60 \mathrm{Mg} \mathrm{ha}^{-1}$ & 1,36 & 1,48 & 1,66 & 1,68 \\
\hline CV (\%) & 6,49 & 5,51 & 6,84 & 5,32 \\
\hline
\end{tabular}

Neste caso, o efeito da matéria orgânica do lodo de esgoto $\left(30\right.$ e $\left.60 \mathrm{Mg} \mathrm{ha}^{-1}\right)$ refletiu positivamente na densidade e porosidade total do solo, e a dose com $60 \mathrm{Mg} \mathrm{ha}^{-1}$ de lodo de esgoto proporcionou melhor efeito.

Verificou-se que os tratamentos estudados não estão modificando a densidade do solo no solo degradado solo exposto, como ocorreu nas demais profundidades, com maior valor comparado ao de Cerrado, confirmando a compactação do solo (Quadro 6). Por outro lado, no contraste solo exposto x demais, houve significância para macroporosidade (exceto profundidade de 0,00-0,05 m), porosidade total e densidade do solo, indicando que, para as profundidades estudadas, essas propriedades estão sendo alteradas, pois diferenciaram da condição do solo exposto.

Houve diferença significativa entre os tratamentos para a produção de matéria verde e seca da braquiária (Quadro 7). Analisando sua produção, verificou-se que o tratamento sem adubação não diferiu estatisticamente do tratamento com adubação mineral. Entre os tratamentos com 30 e $60 \mathrm{Mg} \mathrm{ha}^{-1}$ de lodo de esgoto, também não houve significância para a produção de matéria verde e seca. Contudo, nota-se que maior produção de matéria verde e seca da braquiária ocorreu nos tratamentos que receberam 30 e $60 \mathrm{Mg} \mathrm{ha}^{-1}$ de lodo de esgoto. Resultados semelhantes foram observados por Oliveira et al. (1995), pois a aplicação de lodo de esgoto em doses superiores a $20 \mathrm{Mg} \mathrm{ha}^{-1}$ proporcionou melhores resultados no crsecimento do sorgo granífero. Já
Trannin et al. (2005) verificaram que a adição de $10 \mathrm{Mg} \mathrm{ha}^{-1}$ de lodo de esgoto em base seca, suplementada com $\mathrm{K}_{2} \mathrm{O}$ e $30 \%$ da exigência em $\mathrm{P}_{2} \mathrm{O}_{5}$, proporcionou produtividade de milho equivalente à obtida com adubação mineral completa.

Analisando os efeitos das adubações verdes e orgânicas na produção de braquiária em um Latossolo Vermelho degradado, Suzuki (2005) verificou que, após 274 dias da semeadura, o rendimento da matéria seca da braquiária aumentou aproximadamente 28 vezes, passando de $366 \mathrm{~kg} \mathrm{ha}^{-1}$ aos 88 dias para $10.133 \mathrm{~kg} \mathrm{ha}^{-1}$.

Quadro 7. Rendimento de matéria verde e seca da braquiária avaliada 2,5 anos após a semeadura

\begin{tabular}{lcc}
\hline \multirow{2}{*}{ Tratamento } & Matéria verde & Matéria seca \\
\hline & \multicolumn{2}{c}{$\mathrm{kg} \mathrm{ha}^{-1}$} \\
\cline { 2 - 3 } Solos em adubação & $17.698 \mathrm{~B}$ & $9.780 \mathrm{~B}$ \\
Ad. Mineral & $27.198 \mathrm{~B}$ & $13.236 \mathrm{~B}$ \\
$30 \mathrm{Mg} \mathrm{ha}$ & & \\
$60 \mathrm{Mg} \mathrm{ha}$ & $64.260 \mathrm{~A}$ & $22.023 \mathrm{~A}$ \\
CV (\%) & $66.885 \mathrm{~A}$ & $23.248 \mathrm{~A}$ \\
DMS (5\%) & 47,26 & 33,65 \\
\hline
\end{tabular}

Médias seguidas de letras iguais na coluna não diferem estatisticamente entre si pelo teste de Tukey a $5 \%$. 
Já Alves (2001), estudando a produção de matéria seca, de braquiária num solo em recuperação há sete anos, encontrou produção de $7.000 \mathrm{~kg} \mathrm{ha}^{-1}$, porém sem corte da vegetação no ano. Portanto, analisando os resultados referentes à matéria verde e seca, nota-se que os tratamentos com lodo de esgoto estão propiciando a recuperação do solo degradado.

Houve diferença significativa para a altura das plantas do eucalipto entre os tratamentos estudados (Quadro 8). O tratamento com $60 \mathrm{Mg} \mathrm{ha}^{-1}$ diferiu dos demais e proporcionou maior crescimento do eucalipto, o mesmo ocorrendo para o DAP (diâmetro à altura do peito).

Apesar de não ter ocorrido diferenças entre os tratamentos usados para a recuperação das propriedades físicas do solo, isto é, entre solo cultivado com eucalipto sem adubação, cultivado com adubação mineral e cultivado com lodo de esgoto (duas dosagens), pelos resultados de crescimento de plantas de eucalipto, verificou-se que houve um diferencial para o tratamento com $60 \mathrm{Mg} \mathrm{ha}^{-1}$, provavelmente devido às alterações nas propriedades químicas do solo.

Esses resultados foram concordantes com os de Colodro (2005), que, estudando o efeito do lodo de esgoto sobre a altura e o DAP, observou que os tratamentos com lodo de esgoto promoveram melhor crescimento e maior diâmetro das plantas de eucalipto e que a dose de lodo de $60 \mathrm{Mg}$ ha ${ }^{-1}$ foi significativamente superior à de todos os demais tratamentos. Segundo Rocha et al. (2004), a adição do lodo de esgoto influenciou positivamente a nutrição das plantas, gerando uma produção de madeira semelhante à obtida no tratamento que só recebeu adubação mineral com uma

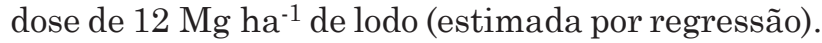
A produção máxima estimada de madeira $\left(45,5 \mathrm{Mg} \mathrm{ha}^{-1}\right)$ seria conseguida com a aplicação de $37 \mathrm{Mg} \mathrm{ha}^{-1}$ de lodo de esgoto.

Quadro 8. Valores médios para altura e diâmetro do caule das plantas de eucalipto aos 2,5 anos após o plantio

\begin{tabular}{lcc}
\hline Tratamento & Altura & DAP \\
\hline & $\mathrm{m}$ & $\mathrm{cm}$ \\
Solos em adubação & $3,14 \mathrm{~B}$ & $2,61 \mathrm{~B}$ \\
Ad. Mineral & $3,54 \mathrm{~B}$ & $2,78 \mathrm{~B}$ \\
$30 \mathrm{Mg} \mathrm{ha}^{-1}$ & $3,99 \mathrm{~B}$ & $3,28 \mathrm{~B}$ \\
$60 \mathrm{Mg} \mathrm{ha}^{-1}$ & $5,94 \mathrm{~A}$ & $5,56 \mathrm{~A}$ \\
CV (\%) & 18,45 & 23,39 \\
DMS (5\%) & 1,70 & 0,01 \\
\hline
\end{tabular}

Médias seguidas de letras iguais na coluna não diferem estatisticamente entre si pelo teste de Tukey a $5 \%$.

\section{CONCLUSÕES}

1. O lodo de esgoto influenciou as propriedades físicas do solo, quando comparado o solo exposto (sem tratamento para recuperação) e o solo que recebeu tratamentos para recuperação, cultivado com eucalipto e braquiária.

2. A densidade do solo, a porosidade total e a macroporosidade foram melhores indicadores da recuperação do solo.

3. O uso de lodo de esgoto proporcionou maior rendimento de matéria verde e seca da braquiária e promoveu maior crescimento das plantas de eucalipto.

\section{LITERATURA CITADA}

ALVES, M.C. Cultura do algodão, soja, milho e feijão em sucessão com quatro adubos verdes em dois sistemas de semeadura. Piracicaba, Escola Superior de Agricultura Luiz de Queiroz, 1992. 173p. (Tese de Doutorado)

ALVES, M.C. Recuperação do subsolo de um Latossolo Vermelho usado para terrapleno e fundação da usina hidrelétrica de Ilha Solteira - SP. Ilha Solteira, Universidade Estadual Paulista, 2001. 83p. (Tese de Livre Docência)

ALVES, M.C.; SUZUKI, L.G.A. \& SUZUKI, L.E.A.S. Densidade do solo e infiltração de água como indicadores da qualidade física de um Latossolo Vermelho distrófico em recuperação. R. Bras. Ci. Solo, 31:617-625, 2007.

BARBOSA, G.M.C.; TAVARES FILHO, J. \& FONSECA, I.C.B. Avaliações de propriedades físicas de um Latossolo Vermelho eutroférrico tratado com lodo de esgoto por dois anos consecutivos. Sanare, 17:94-101, 2002.

BAVER, L.D.; GARDNER, W.H. \& GARDNER, W.R. Soil physics. 4.ed. New York, John Wiley \& Sons, 1972. 529p.

COLODRO, G. Recuperação de solo de área de empréstimo com lodo de esgoto. Campinas, Universidade Estadual de Campinas, 2005. 82p. (Tese de Doutorado)

COLODRO, G. \& ESPINDOLA, C.R. Alterações na fertilidade de um Latossolo degradado em resposta à aplicação de lodo de esgoto. Acta Sci. Agron., 28:1-15, 2006.

DE MARIA, I.C.; CASTRO, O.M. \& SOUZA DIAS, H. Atributos físicos do solo e crescimento radicular de soja em Latossolo Roxo sob diferentes métodos de preparo do solo. R. Bras. Ci. Solo, 23:703-709, 1999.

DE MARIA, I.C.; KOCSSIS, M.A. \& DECHEN, S.C.F. Agregação do solo em área que recebeu lodo de esgoto. Bragantia, 66:291-298, 2007.

DEMATTÊ, J.L.I. Levantamento detalhado dos solos do Campus Experimental de Ilha Solteira. Piracicaba, 1980. 131p. (Não Publicado) 
EMPRESA BRASILEIRA DE PESQUISA AGROPECUÁRIA . EMBRAPA. Centro Nacional de Pesquisa de Solos. Manual de métodos de análise de solo. 2.ed. Rio de Janeiro, 1997. $212 \mathrm{p}$

EMPRESA BRASILEIRA DE PESQUISA AGROPECUÁRIA EMBRAPA. Sistema brasileiro de classificação de solos. Rio de Janeiro, 1999. 412p.

GREENLAND, D.J. Soil management and soil degradation. J. Soil Sci., 31:301-322, 1981.

KIEHL, E.J. Manual de edafologia: Relação solo-água-planta. São Paulo, Agronômica Ceres, 1979. 262p.

JORGE, J.A.; CAMARGO, O.A. \& VALADARES, J.M.A.S. Condições físicas de um Latossolo Vermelho-Escuro quatro anos após aplicação de lodo de esgoto e calcário. R. Bras. Ci. Solo, 15:237-240,1991.

LOPES, J.A.V. \& QUEIROZ, S.M.P. Rodovias e meio ambiente no Brasil: Uma resenha crítica. In: RECUPERAÇÃO DE ÁREAS DEGRADADAS, SIMPÓSIO SUL-AMERICANO, 1.; SIMPÓSIO NACIONAL, 2., Curitiba, 1994. Anais... Curitiba, Fundação de Pesquisas Florestais do Paraná, 1994. p.75-90.

MARTENS, D.A. \& FRANKENBERGER JR., W.T. Modification of infiltration rates in a organic-amended irrigated soil. Agron. J., 84:707-717, 1992.

MELLO, F.A.F.; BRASIL SOBRINHO, M.D.C.; ARZOLLA, S.; SILVEIRA, R.I.; NETTO, A.C. \& KIHEL, J.C. Fertilidade do solo. 2.ed. Piracicaba, 1984. 400p.

MELO, V.P.; BEUTLER, A.N.; SOUZA, Z.M.; CENTURION, J.F. \& MELO, W.J. Atributos físicos de Latossolos adubados durante cinco anos com biossólido. Pesq. Agropec. Bras., 39:67-72, 2004.
OLIVEIRA, F.C.; MARQUES, M.O.; BELLINGIERI, P.A. \& PERECIN, D. Lodo de esgoto como fonte de macronutrientes para a cultura do sorgo granífero. Sci. Agríc., 52:360-367, 1995.

PAGLIAI, M.; GUIDI, G.; LA MARCA, M.; GIACHETTI, M. \& LUCAMANTE, G. Effects of sewage sludges and composts on soil porosity and aggregation. J. Environ. Quality,10:556-561, 1981.

ROCHA, G.N.; GONÇALVES, J.L.M. \& MOURA, I.M. Mudanças da fertilidade do solo e crescimento de um povoamento de Eucalyptus grandis fertilizado com biossólido. R. Bras. Ci. Solo, 28:623-639, 2004.

SCHLOTZHAVER, S.D. \& LITTELL, R.C. SAS: System for elementary statistical analysis. 2.ed. Cary, SAS, 1997. 905p.

SUZUKI, L.G.A.S. Recuperação de um solo com adubo verde, lodo de esgoto e revegetado com uma espécie arbórea. Ilha Solteira, Universidade Estadual Paulista, 2005. 55p. (Trabalho de Graduação)

TRANNIN, I.C.B.; SIQUEIRA, J.O. \& MOREIRA, F.M.S. Avaliação agronômica de um biossólido industrial para a cultura do milho. Pesq. Agropec. Bras., 40:261-269, 2005.

TSUTIYA, M.T. Alternativas de disposição final de biossólido. In: TSUTIYA, M.T.; COMPARINI, J.B.; SOBRINHO, P.A.; HESPANHOL, I.; CARVALHO, P.C.T.; MELFI, A.J.; MELO, W.J. \& MARQUES, M.O., eds. Biossólidos na agricultura. São Paulo, SABESP, Escola Politécnica - USP, ESALQ, UNESP, 2001. p.133-180.

VEIGA, M.; BASSIL, L. \& ROSSO, A. Degradação do solo e da água: Manual de uso, manejo e conservação do solo e da água. 2.ed. Florianópolis, Secretaria da Agricultura e Abastecimento, 1994. 384p. 